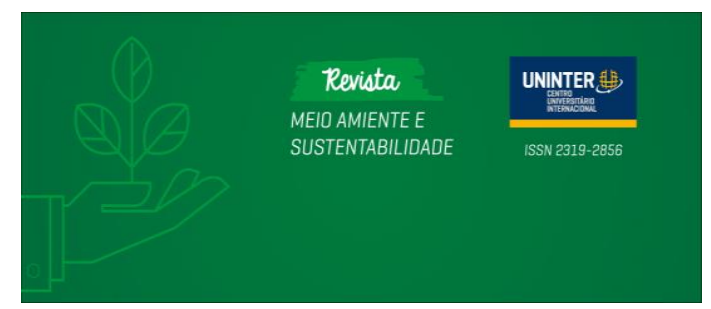

Revista Meio Ambiente e Sustentabilidade

Versão on-line ISSN 2319-2856

Volume 15, número 7. Curitiba - PR. jun/dez - 2018

\title{
O Sistema de Gestão Ambiental segundo a ISO 14.004 como roteiro à Gestão de Ecovilas Brasileiras para Atendimento da Agenda 21 da ONG
}

\section{Luciana Lima Domingues de Souza lucianalimavalinhos@gmail.com}

Advogada e autora do sistema de governança e compliance A Villa mundi, Especialista Perícias e Auditoria Ambiental no Centro Universitário Internacional UNINTER e Licenciada Direito do Trabalho FDDJ, Graduada Direito na PUCCAMP e Industriekaufmann (Administração de Empresas) na AHK/IFPA/DIHT, Alemanha,

\section{Rafael Lopes Ferreira rafa.gestor_amb@hotmail.com}

Professor orientador Gestor Ambiental (Faculdades Integradas Camões/PR), Especialista Biotecnologia (PUC PR), Mestrando Ciência e Tecnologia Ambiental (UTFPR), orientador TCC Centro Universitário Internacional UNINTER

\section{RESUMO}

Com a Agenda 21 na Eco92, as ecovilas foram nomeadas oficialmente pela ONU como melhor prática de viver social e ambientalmente sustentável. Estima-se, hoje, existirem cerca de 15.000 ecovilas em todo o globo, sendo 2.300 apenas no Brasil. Porém, em sua maior parte, as ecovilas não atendem a quesitos mínimos de sustentabilidade, quiçá à transparência em seus processos e relações. Este estudo traz a reflexão acerca do sistema de gestão ambiental, conforme a ISO 14.004, como um roteiro paradigma para o atendimento da Agenda 21. Objetiva-se constatar se o sistema de gestão ambiental segundo a norma atenderia os ditames da Agenda 21 da ONU, identificando requisitos legais e normativos, bem como apresentando uma proposta de avaliação preliminar socioambiental. Para a realização deste trabalho, serão feitas pesquisas bibliográficas a partir de livros, revistas, artigos, websites e trabalhos científicos relacionados a ecovilas e outras organizações no Brasil, além de consultas a legislações, normas, manuais de boas práticas, documentos governamentais e de instituições do terceiro setor, privilegiando-se como referência a norma regulamentadora ISO14.004. A gestão ambiental é parte integrante do sistema geral de uma organização, um processo contínuo e interativo. Nesse contexto, acompanhar a qualidade ambiental de processos e gestão das próprias atividades, produtos e serviços, atendendo a leis e normas, deve ser meta também de ecovilas através da codificação única e reconhecida mundialmente, qual seja, a da norma ISO.

Palavras-chave: Sustentabilidade. Direito Ambiental. Políticas Públicas. Ecovilas 


\title{
The Environmental Management System of Iso 14.004 as a Management Guidance For Brazilian Ecovillages To Meet Agenda 21 Goals
}

\begin{abstract}
With Agenda 21 at Eco92, UN officially named the sustainable human settlements as the best practice in living on social and environmental sustainability basis. It is estimated that today there are around 15,000 sustainable communities around the globe, of which 2,300 are only in Brazil. However, for the most part, these communities do not meet minimum sustainability requirements or transparency criteria in their processes and relationships. The present study aims to reflect on the ISO 14.004 environmental management system as a paradigm guidance for the fulfillment of Agenda 21 purposes. The objective is to verify if the legal requirements presented by ISO 14.004 system meets the Agenda 21 main goals, as well as presenting a proposal for a preliminary socio-environmental evaluation. The present study will be conducted on bibliographical research from books, magazines, articles, websites and scientific papers related to sustainable communities and human settlements in Brazil, and by the examination of the national law, standards, good practices manuals, government and third sector entities documents, with the emphasis being placed on ISO14.004 system. Environmental management is an integral part, and an ongoing process of the overall system of an organization. Environmental management is an integral part of the core business of any organization, and a continuous and systematic process. In this context, to monitor the environmental performance of their processes and manage their own activities, products and services, complying with laws and standards, should be also a goal of any sustainable human settlements in Brazil, mainly through the unique and globally recognized rules, that is, the ISO standards.
\end{abstract}

Keywords: Sustainability. Environmental Law. Public policies. Ecovillages.

\section{INTRODUÇÃO}

Em 1992, com a Conferência da Organização das Nações Unidas para o Meio Ambiente e Desenvolvimento no Rio de Janeiro, a Eco 92 ou Cúpula da Terra, importantes passos foram conferidos às questões ambientais e preservação da natureza (ONU, 2018). Desde esse evento, o mundo identificou um novo caminho para o bem-estar humano e sua perenidade no Planeta: o desenvolvimento sustentável.

Além dos marcos aprovados da biodiversidade e mudanças climáticas na Eco 92, outro resultado foi a assinatura da Agenda 21 Global (UN, 2018), a qual se consubstancia em um plano de ações com metas para a melhoria das condições ambientais do planeta. Tal foi o grau de importância deste documento para a elaboração de estratégias para o desenvolvimento sustentável, que foi assinado por 179 países (MMA, 2018). 
Outro resultado foi a nomeação oficial das ecovilas, ou assentamentos humanos sustentáveis, como melhor prática para o desenvolvimento sustentável e como modelo excelente de vida (ONU, 1995). Desta forma, foi a partir da Eco 92 que se originou o movimento por formação de ecovilas em todo o globo. Estima-se, hoje, existirem cerca de 15.000 ecovilas em todo o globo, sendo 2.300 apenas no Brasil.

$\mathrm{Na}$ busca por alternativas viáveis de sustentabilidade e equacionamento do desenvolvimento econômico, as ecovilas aparecem como um modelo alternativo que procura adotar, em tese, a preservação ambiental e a utilização consciente do ecossistema local, atrelado a redes de permutas, associativismo e construção sustentável.

Segundo BISSOLOTTI (2004), a sustentabilidade norteia as atividades de uma ecovila, desde sua concepção até sua implantação e gerenciamento. Porém, são raras as comunidades realmente sustentáveis, que vivem os ditames da Agenda 21 e a transparência em seus processos e relações essenciais ao cenário em que se inserem.

A busca por excelência em empreendimentos ecológicos e socioambientais sustentáveis devem objetivar a qualidade das relações e o equilíbrio dos aspectos econômico, social e ambiental através de gestão ética e transparente, seja com entes públicos seja com privados, além do estabelecimento de metas ambientais compatíveis com o desenvolvimento sustentável (SOIBERT, 2011).

\section{OBJETIVOS}

O objetivo principal do presente estudo é verificar, no contexto da ISO 14.004 e do seu respectivo sistema de gestão ambiental, os parâmetros normativos e legais, mínimos e gerais, que sirvam como roteiro para as ecovilas operarem à altura de sua nomeação pela ONU na Agenda 21, permanecendo na busca de qualidade e compliance ${ }^{1}$ socioambientais.

Neste sentido, opta-se por iniciar o estudo com a contextualização histórica da Agenda 21, com os significados que a tornam um divisor de águas à governabilidade de países, dentre eles o Brasil, inclusive, servindo como referência a empresas público e privadas, bem como organizações do terceiro setor.

\footnotetext{
${ }^{1}$ Compliance vem do verbo em inglês to comply e significa estar conforme normas, controles internos e externos, trabalhistas, fiscais, contábeis, financeiras, ambientais, jurídicas, éticas, etc.
} 
Busca-se analisar o contexto, propósitos e desenvolvimento supranacional das normas ISO 14.000, fazendo um paralelo com a Agenda 21, para verificar a confluência de ambas e se são as normas uma referência na agenda, podendo assim servir como ferramenta de uniformização, vigilância e gestão socioambiental conforme a Agenda 21 Local preconiza.

Além da avaliação da norma ISO 14.004, analisa-se requisitos legais, os quais poderão corroborar em uma proposta de matriz genérica de interpretação e aplicação normativa para o funcionamento de ecovilas no Brasil. A gestão ambiental é parte integrante do sistema geral de uma organização, um processo contínuo e interativo (ABNT, 2005, p.5).

\section{METODOLOGIA}

A metodologia utilizada para a presente pesquisa foi a revisão bibliográfica, análise de artigos e documentos oficiais, consultas a websites e trabalhos científicos relacionados a ecovilas, assentamentos humanos sustentáveis e outras organizações comunitárias no Brasil, além de consultas a legislações e normas nacionais, tratados internacionais e documentos governamentais, privilegiando-se os documentos que tinham, como referência, a norma regulamentadora ISO14.004.

Ademais, através da revisão bibliográfica, consultas a websites e trabalhos científicos, foi possível elaborar o questionário de avaliação socioambiental preliminar conforme a ISO 14.004 para ecovilas brasileiras, estabelecido em seções.

Destarte, para cada uma das seções mencionadas no questionário, foram criadas perguntas acerca de ações hipotéticas em ecovilas, positivas ou negativas, sendo que, para cada um dos questionamentos, foram preparadas quatro alternativas como respostas: conforme, não conforme, não verificado ou não pertinente.

Adicionalmente, foi elaborada uma pesquisa jurisprudencial nos tribunais de justiça e cortes superiores do Brasil em busca lides ativas e arquivadas, em que comunidades sustentáveis, institutos ou ecovilas constam como autor ou réu nos últimos 10 anos.

No Superior Tribunal de Justiça, acessou-se julgados relacionados a danos ambientais de particulares em assentamentos, como o AREsp n839.492 SP, assim como 
infrações relacionadas a compliance de ecovilas em serviços ambientais prestados, como o ocorrido com a Ecovila IPOEMA no REsp n¹.629.980 DF.

Finalmente com relação às desavenças internas por falta de transparência e regras claras, foi investigado a fundo o ocorrido com a Ecovila Arco-Íris, obrigada a indenizar quatro membros pelas cotas patrimoniais adquiridas, segundo o Processo $\mathrm{n}^{\circ}$ 201300591808, que tramita em Cavalcanti/GO. Isso sem falar em ecovilas enquadradas judicialmente como "loteamento clandestino" ou "condomínio irregular”.

\section{CONTEXTO HISTÓRICO DA AGENDA 21}

O planeta atravessa uma grave crise ambiental resultante da intervenção humana, do desenvolvimento econômico com base no lucro e das externalidades produzidas pela sociedade contemporânea.

Na década de 70, um grupo de cientistas do Massachusetts Institute of Technology (MIT), sob o comando de Dennis Meadows, publicou o relatório The Limits of Growth em 1972. Para SAES E MIYAMOTO (2012)

\footnotetext{
Assim, segundo Meadows et al. (1973 [1972]), os problemas fundamentais enfrentados pela sociedade decorreriam da manutenção de um crescimento econômico ilimitado frente à existência de um planeta com recursos naturais infinitos. O crescimento exponencial do consumo e da população levaria à exaustão dos recursos do planeta e a crescentes níveis de poluição em um futuro não muito distante.
}

Em 1983, a Dra. Brundtland presidiu a Comissão Mundial sobre o Meio Ambiente e Desenvolvimento e, em 1987, publicou o relatório “Nosso Futuro Comum”, que trouxe o conceito de desenvolvimento sustentável aceito ainda hoje por todas as nações mundiais como sendo o desenvolvimento que encontra as necessidades atuais sem comprometer a habilidade das futuras gerações de atender suas próprias necessidades (ONU, 2018). A partir de então, o assunto "desenvolvimento sustentável” passou à agenda pública de inúmeros países, o que levou à convocação da Cúpula da Terra em 1992. 
Por pesquisa, sabe-se que foi na Cúpula da Terra que a Agenda 21 foi apresentada, sendo ela um documento que se assemelha a um diagrama para a proteção do nosso planeta e ao desenvolvimento sustentável, consolidando duas décadas de trabalho iniciado desde Estocolmo, em 1972. Para os congressistas da Eco 92, a Agenda 21 é um verdadeiro codex de avaliação e vigilância para sustentação da vida na Terra (ONU, 2018).

A Agenda 21 foi o documento assinado por 179 países em 14 de junho de 1992, no Rio de Janeiro, podendo ser definida como um instrumento de planejamento para a construção de sociedades sustentáveis em diferentes bases geográficas, que concilia métodos de proteção ambiental, justiça social e eficiência econômica (MMA, 2018).

Trata-se de um documento programático a ser implementado pelos Estados, agências, ONU, entidades de classe e empresas. Quanto à sua juridicidade, a Agenda 21 não é uma declaração ou uma convenção internacional, porém pode ser enquadrada como soft $l a w^{2}$.

Porém, a Eco 92 e Agenda 21 deixaram sua marca como um divisor de águas na consolidação e evolução do Direito Internacional Ambiental e pela mudança da ênfase no conteúdo de suas normas, que passaram a consagrar o enfoque da necessidade de regulamentações que dessem maior vigor ao conceito de justiça nas relações internacionais (SOARES, 2001).

As relações entre países pobres e ricos passaram a ser conduzidas por um novo conjunto de princípios inovadores como o do "poluidor pagador" e dos "padrões sustentáveis de produção e consumo." Outro aspecto relevante foi a participação de organizações não-governamentais, que passaram a atuar como fiscais ou pressionando Estados para o cumprimento da Agenda 21, como o Greenpeace, World Wild Foundation e Conselho Internacional para Iniciativas Ambientais Locais (ICLEI).

Em solo nacional, houve progressos igualmente com a edição da Resolução Conama 237/1997, que regulamentou a revisão do Licenciamento Ambiental como instrumento de gestão ambiental, a Lei dos Crimes Ambientais n.9.605/1998, a Política Nacional da Educação Ambiental Lei nº 9.795/1999, o Estatuto da Cidade Lei nº 10.257/2001 e o Instituto Chico Mendes de Conservação da Biodiversidade ICMBio Lei nº. 11.516/2007.

\footnotetext{
2 "Soft law", termo em inglês, significa os instrumentos de direito de caráter não obrigatório, porém dotados de juridicidade (tradução nossa).
} 
Para Novaes (2000), não há como tal documento existir, perenizar e se tornar cogente se não houvesse o envolvimento da comunidade internacional na Ecog2. Destarte, a Agenda 21 Global, ou Cúpula da Terra, deu origem às Agendas 21 Locais, como a do Brasil também conhecida como Carta da Terra. Para o governo brasileiro,

a construção da Agenda 21 Local vem ao encontro com a necessidade de se construir instrumentos de gestão e planejamento para o desenvolvimento sustentável. O processo de Agenda 21 Local

pode começar tanto por iniciativa do poder público quanto da sociedade civil. De fato, a Agenda 21 Local é processo e documento de referência para Planos Diretores e orçamento municipais, entre outros, podendo também ser desenvolvida por comunidades rurais, e em diferentes territorialidades, em bairros, áreas protegidas, bacias hidrográficas (MMA, 2018).

Portanto, a Agenda 21 Brasileira incorpora o conceito de sustentabilidade ao desenvolvimento brasileiro, estabelecendo estratégias de gestão e monitoramento ambiental mediante indicadores de sustentabilidade dentro de cada um dos eixos temáticos.

O eixo "Gestão dos Recursos Naturais - Estratégia 4" da agenda local referenda as certificações ISO 9.000 e 14.000 como medidas de controle da qualidade ambiental para a proteção e disciplina no uso dos recursos naturais e da proteção da atmosfera global, ressaltando a necessidade de promoção da eficiência na produção e no consumo de energia (NOVAES, 2000).

Proposta de ações

- Participação da sociedade civil local no monitoramento e na fiscalização do uso dos recursos naturais: desenvolvimento de programas de sensibilização e capacitação de entidades da sociedade civil em práticas de monitoramento e fiscalização do uso dos recursos naturais.

- Estimulo a práticas de obtenção de certificados ISO 9.000 e 14.000: implica a disseminação dos procedimentos e das possibilidades comerciais a eles associadas (NOVAES, 2000, p.39).

Por outro lado, no eixo da "Infraestrutura e integração regional", a "Agenda 3 Informação e Conhecimento" estipula como diretriz ampliar os sistemas de certificação da qualidade de produtos, serviços e sistemas de gestão com o objetivo de assegurar os direitos dos consumidores (NOVAES, 2000, p.56). 
Adicionalmente, no eixo da "Redução das desigualdades sociais", a “Estratégia 2" propõe a concentração de ações na difusão das boas práticas a reforçar o potencial das comunidades em benefício próprio para fortalecimento da dimensão local através de um desenvolvimento local integrado e sustentável (NOVAES, 2000).

Observa-se que há uma conexão entre a Agenda 21 Global e Brasileira com o grupo de normas ISO14.000, sendo as normas referenciadas pela própria agenda como mecanismo norteador de boas práticas socioambientais.

A questão da gestão, como ponto emblemático ao desenvolvimento sustentável, propicia a dedução de que a gestão socioambiental de ecovilas pela ISO14.004 seria algo adequado e suficiente à programação global em prol da sustentabilidade conforme Agenda 21 Global e Brasileira.

\section{A ISO 14.004 E O SISTEMA DE GESTÃO AMBIENTAL}

Somente através da avaliação da norma ISO14.004, de requisitos legais e outros aplicáveis a ecovilas e comunidades sustentáveis no Brasil, é possível elaborar uma proposta de matriz genérica normativa para o funcionamento dessas entidades.

Com base em pesquisa histórica, no pós-guerra de 1947, foi criada a "International Organization for Standartization (ISO)", objetivando o desenvolvimento da normalização e atividades relacionadas, para facilitar as trocas de bens e serviços no mercado internacional e a cooperação entre os países nas esferas científicas, tecnológicas e produtivas (PERES et al., 2010).

O Comitê 207 da ISO editou as primeiras normas sobre gestão ambiental em 1996: a ISO14.001 e 14.004, ambas acerca de Sistema de Gestão Ambiental (SGA). Até 2004, já existia um sistema de 25 normas publicadas, todas tendo por base o Ciclo Plan-Do-Check$\operatorname{Act}(\mathrm{PDCA})^{3}$.

As normas de gestão são autônomas, podendo ser implementadas de modo isolado. No Brasil, o órgão responsável pela normalização ambiental é a Associação Brasileira de Normas Técnicas (ABNT). Desse esforço nasceram as normas NBR-ISO.

\footnotetext{
3 O Ciclo PDCA é uma metodologia de gestão com objetivo de melhoria contínua dos processos por meio de um circuito de quatro ações: planejar (plan), fazer (do), checar (check) e agir (act).
} 
Ao longo da sua existência, observou-se na ISO uma mudança no foco das certificações, visando certificar o sistema de produção ao invés do produto. Essa mudança foi provocada por diversos fatores: exigência do consumidor final em adquirir um produto ecologicamente aceitável e menos danoso ao meio ambiente; incremento e maior complexidade das legislações ambientais após a Rio 92; preocupações dos investidores financeiros com os passivos ambientais. (PERES et al, 2010).

Segundo Harrington e Knight (2001), constata-se que a ISO 14.004 é de grande ajuda para as organizações com pouca ou nenhuma experiência com SGA, pois sendo norma de padrão informativo, que estabelece as diretrizes do sistema de gestão ambiental, tem a finalidade de orientação e não de certificação por auditoria externa.

\section{ECOVILAS E A NORMA ISO 14.004}

Existe um conceito genérico de ecovilas que a define como comunidade organizada para fazer a transição para uma sociedade sustentável (GOLDSTEIN, 2010).

Nesse estudo, ecovilas e comunidades sustentáveis serão tratadas como sinônimos, podendo ser definidas como comunidades humanas rurais ou urbanas, que almejam integrar um ambiente socioambiental a uma vida de baixo impacto ambiental, dotada de multiculturalismo.

Por sua vez, o SGA se adapta às organizações, portanto, ao propor sua implantação, cada organização deve definir e documentar o escopo do sistema, isto é, seus limites dentro dos quais todas as atividades, produtos e serviços estarão abarcados pelo sistema de gestão (MELO, RAPÉ, 2015).

Segundo a norma ISO 14.004, o SGA é a forma de sistematizar a prática da gestão ambiental, sendo uma ferramenta para auxiliar as entidades e corporações a implantar a gestão ambiental em suas operações.

Nesse sentido, considerando a amplitude do trabalho apresentado, o presente estudo se restringiu a levantar, em nível federal, a legislação classificada por tipos de normas, como lei ordinária, regulamento, norma, tratado internacional e nacionalizado aplicável, propondo-se o seguinte esquema hierárquico para interpretação das exigências:

Quadro 1: Estrutura hierárquica legal e normativa para ecovilas e comunidades sustentáveis no Brasil.

\begin{tabular}{|l|l|}
\hline $\begin{array}{l}\text { Nível } \\
\text { hierárquico }\end{array}$ & Legislação, normas e tratados \\
\hline
\end{tabular}




\begin{tabular}{|c|c|}
\hline $\begin{array}{l}\text { Nível } 1 \text { ou } \\
\text { superior }\end{array}$ & $\begin{array}{l}\text { Legislação federal e de suas agências, ministérios, departamentos e } \\
\text { órgãos federativos, Agenda } 21 \text { Brasileira, tratados internacionais e } \\
\text { nacionalizados. }\end{array}$ \\
\hline Nível 2 & $\begin{array}{l}\text { Legislação e normas da Corregedoria, agências, departamentos e órgãos } \\
\text { do Estado de sede da ecovila. }\end{array}$ \\
\hline Nível 3 & $\begin{array}{l}\text { Normas ABNT ISO } 14.004 \text { e outras normas regulamentadoras aplicáveis à } \\
\text { construção civil, infraestrutura, subsolos, projetos arquitetônicos, } \\
\text { hidráulicos, elétricos, sinalização interna e externa, etc. }\end{array}$ \\
\hline Nível 4 & $\begin{array}{l}\text { Legislação e normas municipais: Plano Diretor, Código Tributário } \\
\text { Municipal, portarias da Secretaria de Habitação e Meio Ambiente, etc. }\end{array}$ \\
\hline Nível 5 & $\begin{array}{l}\text { Manuais de boas práticas, tais como: Manual de Governança Corporativa, } \\
\text { Manual de Governança Cooperativa, Manuais da Vigilância Sanitária, etc. }\end{array}$ \\
\hline Nível 6 & $\begin{array}{l}\text { Missão, visão, valores, propósitos institucionais, regulamento interno e } \\
\text { código de ética da ecovila, política ambiental e política de governança da } \\
\text { ecovila. }\end{array}$ \\
\hline
\end{tabular}

Fonte: elaborado pela autora.

A ordem de interpretação e aplicação da legislação face o SGA se dá a partir do Nível 1, sendo este o patamar das leis e normas superiores e cogentes em relação aos demais níveis inferiores subsequentes, ou seja, os Níveis 2, 3, 4. 5 e 6. Os documentos, regras e procedimentos que forem produzidos no nível 6 deverão observar, de plano, as leis, normas e tratados dos níveis hierarquicamente superiores.

Considerando o complexo ordenamento jurídico brasileiro sob pacto federativo, foi apresentada pela autora a estrutura hierárquica legal e normativa do Quadro 1 como primeiro passo às ecovilas. Assim, com base na Quadro 1, é possível compreender porque a legislação federal e regulamentos de agências e órgãos ambientais, como o CONAMA 4 que, ao lado da Agenda 21 Brasileira, prepondera sobre eventuais dispositivos normativos contraditórios contidos em regulamentos ou na norma ISO 14.004.

Claro que a proposta da autora deverá ser aplicada com parcimônia, pois podem haver casos em que as normas inferiores ou de competência residual venham a se sobrepor às demais por nomeação ou outorga federal ou estadual. Apenas um advogado especialista para aplicar a interpretação correta diante de tais cenários excepcionais.

\footnotetext{
4 "CONAMA" é a abreviatura de Conselho Nacional do Meio Ambiente, criado na Política Nacional do Meio Ambiente Lei $n^{\circ}$. 6.938, de 31.08.1981.
} 
Já para a implantação do SGA, é sugerido pela autora que a ecovila percorra o seguinte roteiro: a) estabelecimento da política ambiental; b) identificação dos aspectos ambientais de suas atividades, produtos e serviços, atuais ou futuros, para determinar os impactos e eventuais danos socioambientais significativos; c) discriminação dos requisitos legais aplicáveis, conforme a estrutura hierárquica legal e normativa aqui proposta; d) indicação das prioridades, objetivos e metas socioambientais; e) construção da estrutura, programas e sistemas pertinentes ao SGA, para implementação da política ambiental e metas de desempenho socioambiental, sabendo-se que a melhoria é permanente.

Com relação ao roteiro de implantação do SGA e questionário ambiental preliminar, recomenda-se que sejam implantados tendo como referência assentamentos do mesmo estado de implantação ou funcionamento, analisando-se os documentos institucionais das entidades comunitárias ou sem fins econômicos ali instaladas.

Aconselha-se, principalmente, que se consolide uma amostra documental de entidades paradigmas com, em média, 5 anos de operação, mediante levantamento de dados de lides judiciais e extrajudiciais dessas entidades.

Esta recomendação se deve ao fato de que lides judiciais e extrajudiciais corroboraram na previsão e mitigação de riscos, aprendendo-se pelo exemplo. Este tipo de informação colabora, inclusive, na construção de caminhos alternativos de solução de disputas socioambientais.

Por outro lado, antes de iniciar a implantação do sistema de gestão, é recomendado que a ecovila, que ainda não tenha um SGA, faça um diagnóstico inicial para levantar a situação presente em relação ao meio ambiente, cobrindo, no mínimo, as seguintes áreas: (a) identificação dos aspectos ambientais, considerando as condições normais e anormais de operação, incluindo partidas, paradas, situações de emergência e de acidentes; (b) identificação dos requisitos legais e normativos aplicáveis; (c) exame das práticas e procedimentos ambientais existentes, inclusive as associadas à aquisição e contratação de serviços; e (d) avaliação das situações de emergência e acidentes ocorridos anteriormente (BARBIERI, 2012). A esse diagnóstico inicial denominamos "Questionário Ambiental Preliminar".

Considerando o contexto simples de operações de ecovilas, a proposta é um questionário dividido por seções de quesitos, sendo estas: Seção 1 Sistema de Gestão 
Ambiental; Seção 2 Política Socioambiental; Seção 3 Aspectos Ambientais: Produtos químicos tóxicos e perigosos: efluentes líquidos, efluentes sólidos, efluentes gasosos, campanha de reciclagem; Seção 4 Requisitos legais e outros requisitos formais; Seção 5 Objetivos e metas socioambientais; Seção 6 Programa de Gestão Ambiental; Seção 7 Funções e responsabilidades perante o SGA; Seção 8 Treinamento, conscientização e competência; Seção 9 Comunicações; Seção 10 Documentação do sistema de gestão e gestão do conhecimento; Seção 11 Controle de documentos; Seção 12 Controle operacional; Seção 13 Preparação e atendimento a emergências; Seção 14 Monitoramento e medição; Seção 15 Não conformidades, ações corretivas e preventivas; Seção 16 Registros socioambientais; Seção 17 Assembleias Gerais; e Seção 18 Análises críticas pela administração, fundadores e conselheiros.

\section{CONSIDERAÇÕES FINAIS}

O presente trabalho procurou refletir acerca dos parâmetros normativos e legais mínimos e gerais no contexto da ISO 14.004 e do sistema de gestão ambiental, como roteiro para atendimento da Agenda 21 da ONU por ecovilas e comunidades sustentáveis nacionais em busca da qualidade e desempenho socioambiental.

Através do levantamento histórico do movimento ambiental global, que culminou na Agenda 21 como resultado da Rio 92, e posteriormente nas Agendas 21 Locais, foi possível verificar a importância desse codex aos países e a instituições públicas, privadas, com ou sem fins econômicos, que buscam se ajustar a uma economia de transição para o desenvolvimento sustentável. Foi na mesma Eco 92 que as ecovilas foram nomeadas como melhor prática para o desenvolvimento sustentável e como modelo excelente de vida.

Com base no levantamento histórico e do conteúdo programático da Agenda 21 Global e da Brasileira, denominada Carta da Terra, são as normas das famílias ISO 9.000 e 14.000 referenciadas por ambas as agendas como parâmetros normativos mínimos e essenciais para se guiar, monitorar, avaliar e medir o desempenho e a qualidade ambiental de qualquer instituição, pública ou privada, com ou sem fins econômicos rumo ao desenvolvimento sustentável. 
Especialmente com relação à Carta da Terra, em análise às seções "Gestão dos Recursos Naturais - Estratégia 4" e "Agenda 3 - Informação e Conhecimento" do eixo temático da "Infraestrutura e integração regional", constatou-se serem as Normas ISO 14.000 ferramentas de padronização, vigilância, monitoramento e avaliação socioambiental para todo tipo de organização, ecovila ou não.

Nesse sentido, é possível concluir que, tanto o SGA quanto a ISO 14.004, são referência e roteiro à gestão socioambiental de ecovilas brasileiras, por indicar os parâmetros legais e normativos essenciais às operações desses assentamentos rumo à qualidade e desempenho socioambiental pactuado na Agenda 21 Brasileira em vigor até os dias atuais.

A proposta do SGA em ecovilas nacionais deve-se à ISO 14.004 descrever os elementos do sistema e apresentar orientação prática de implementação ou aprimoramento para qualquer tipo de organização, cultura, propósito, estrutura e porte. Estes fatos propiciam a continuidade desta pesquisa em estudos futuros, possibilitando sua evolução e aprofundamento para a composição de SGA próprio a ser aplicado a ecovilas no Brasil.

Por outro lado, através da observação da autora durante dez anos de consultoria técnico-jurídica realizada em ecovilas no Estado de São Paulo, constatou-se que, de modo geral, as pessoas consideram que essas comunidades não causam impactos ou danos ambientais por serem sustentáveis. Porém, o que se verifica na prática é que, ao intervirem no meio ambiente para sua operação, a ecovila já causa desequilíbrios, podendo afetar, inclusive, a saúde humana.

Finalmente, é urgente conscientizar a população de que ecovilas, para se nomearem sustentáveis, precisam conduzir, avaliar e monitorar suas atividades de forma sistematizada, transparente e padronizada através de um SGA. Somente assim será possível ter a certeza de se estar criando uma instituição que caminha rumo ao desenvolvimento sustentável tal qual preconiza a Agenda 21.

\section{REFERÊNCIAS}

ASSOCIAÇÃO BRASILEIRA DE NORMAS TÉCNICAS. ISO 14004. Rio de janeiro. 45 p. 2005. 
BARBIERE, J. C. Gestão Ambiental Empresarial: conceitos, modelos e instrumentos. São Paulo: Saraiva, 2012.

BISSOLOTTI, Paula M. A. Ecovilas: um método de avaliação de desempenho da sustentabilidade. 2004. 151 f. Dissertação. Programa Pós-Graduação da Universidade Federal Santa Catarina. Florianópolis. Disponível: <https://repositorio.ufsc.br/xmlui/handle/123456789/86863>. Acesso: 24.09.2018.

GOLDSTEIN, Suzy. Um fazer diferente: vida em ecovila. Campinas: Pontes, 2010.

HARRINGTON, H. James; KNIGHT, Alan. A implementação da ISO 14000: como atualizar o sistema de gestão ambiental com eficácia. São Paulo: Atlas, 2001.

MELO, Guilherme B.; RAPÉ, Sara F. L. Turismo e gestão ambiental benefícios de um sistema de gestão ambiental para hostel. Artigo apresentado no IX Fórum Internacional Turismo do Iguassu. Foz do Iguaçu. 2015.

MINISTÉRIO DO MEIO AMBIENTE. Agenda 21 local. Disponível: <http://www.mma.gov.br/responsabilidade-socioambiental/agenda-21/agenda-21-local>. Acesso em: 16.03.2018.

A Agenda 21 Brasileira: avaliação e resultados. Disponível: <http://www.terrabrasilis.org.br/ecotecadigital/pdf/agenda-21-brasileira-avaliacao-eresultados-.pdf >. Acesso: 24.09.2018.

NOVAES, W. (Coord.); RIBAS, O.; NOVAES, P. C. Agenda 21 Brasileira: bases para discussão. Brasília: MMA/PNUD, 2000.

ORGANIZAÇÃO DAS NAÇÕES UNIDAS. ECO 92 Cúpula da Terra. Disponível: <https://nacoesunidas.org/acao/meio-ambiente/>. Acesso: 16.03.2018.

- Conferência das Nações Unidas sobre o meio ambiente e desenvolvimento: a Agenda 21. Brasília: Câmara dos Deputados, Coordenação de Publicações, 1995.

PERES, Waldir R. et al. As normas da série ISO 14.000: contexto histórico e análise crítica. Artigo apresentado VI Congresso Nacional Excelência em Gestão. Niterói: 2010.

SAES, Beatriz M.; MIYAMOTO, Bruno César B. Limites físicos do crescimento econômico e progresso tecnológico: o debate The Limits to Growth versus Sussex. Desenvolvimento e Meio ambiente. Curitiba, v.26, jul/dez 2012, p.51-68.

SOARES, Guido F. S. Direito Internacional do Meio Ambiente: emergência, obrigações e responsabilidade. São Paulo: Atlas, 2001. 
SOIBERT, A. T. Capitalismo sustentável: uma mudança nos paradigmas do capitalismo clássico. Vitória: Instituto Superior Educação Afonso Cláudio, 2011.

SUPERIOR TRIBUNAL DE JUSTIÇA. AREsp n839.492 SP. Claudio Steiner versus MP SP. Relator Min. Herman Benjamin. Publicação: 18/05/2016. Disponível: $<$ http://www.stj.jus.br/SCON/decisoes/toc.jsp?livre=REsp+1079713\%2FSC\&\&b=DTXT\&thesa urus=JURIDICO\&p=true $>$. Acesso: 28.09.2018.

. REsp n 1.629.980 DF. IPOEMA versus Cia Saneamento Ambiental DF. Relator: Min. Gurgel Faria. Publicação: 05.06.2018. Disponível: $<$ http://www.stj.jus.br/SCON/decisoes/toc.jsp?livre=ecovila\&\&b=DTXT\&thesaurus=JURIDI CO\&p=true $>$. Acesso: 28.09.2018.

TRIBUNAL DE JUSTIÇA GOIÁS. Processo $\mathbf{n}^{\circ}$. 201300591808. Luis F. Matosinhos e outros versus Ecovila Arco-Íris, Aurimar M. Mello. Juiz: Dr. Pedro P. Cesario Pereira. Cavalcante/GO, $1^{\mathrm{a}} \quad$ Vara Cível. Publicação: 28.11.2016. Disponível: <http://sv-natwebpoo.tjgo.jus.br/spg/Consulta_Opcoes.php>. Acesso: 28.09.2018.

United Nations. Agenda 21 Rio declaration. Disponível: <http://www.undocuments.net/agenda21.htm>. Acesso: 24.09.2018. 